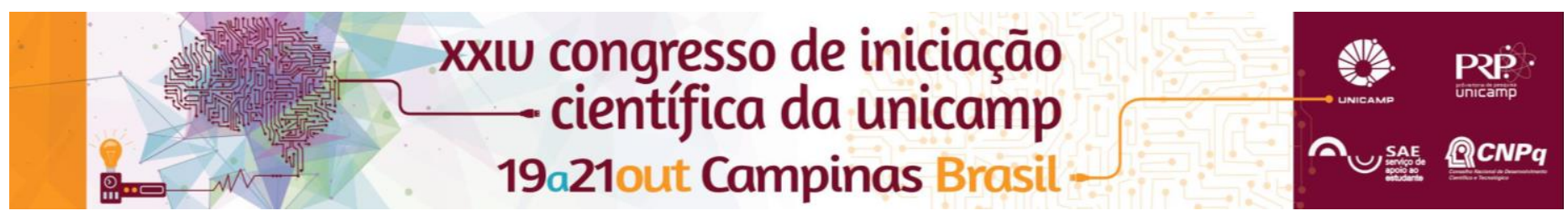

\title{
Desenvolvimento de software para Placa de Contagem em plataforma Arduíno.
}

\author{
Kevin Nogueira Moreira*, Pedro Henrique Silva Oliveira, Prof. Dr. Cristiano de Mello Gallep.
}

\section{Resumo}

Neste trabalho foram desenvolvidos softwares de linguagem $\mathrm{C}$ e de Java, para a interface gráfica de usuário (GUI). Os supracitados foram usados para configurar e operar um sistema eletrônico de baixo custo desenvolvido usando um microcontrolador Arduíno, com o objetivo de substituir a placa de contagem de pulsos previamente utilizada, que devido ao seu alto custo, dificulta o acesso a pesquisas na área de biofotonica. Esta placa, conectada a um computador para o seu manuseio, conta os pulsos de um tubo fotomultiplicador (PMT), que faz a medição da emissão espontânea de biofotons em sementes germinando em uma câmara escura no Laboratório de Fotônica Aplicada (LaFA).

\section{Palavras-chave:}

Arduino, Biofotons, Software.

\section{Introdução}

$O$ código criado em linguagem $C$ funciona como um preset do sistema eletrônico utilizado, é nele que estão os comandos que irão ditar como o micro controlador opera e realiza a contagem de pulsos em si, que acontece através das rotinas de interrupção do micro controlador Arduíno [1].

O software em java por sua vez, foi desenvolvido na plataforma Processing para servir como uma interface gráfica de usuário (GUI) em que o indivíduo irá, usando um computador, configurar o modo e período para a aquisição de dados, ou seja, o intervalo de tempo de um loop de contagem e a quantidade de loops em dado experimento. Dessa forma será possível acompanhar em tempo real a contagem de pulsos através de um gráfico "loops $x$ tempo".

\section{Resultados e Discussão}

O Arduíno foi configurado em $C$ através de seu Ambiente de Desenvolvimento Integrado (IDE). A contagem de pulsos é feita utilizando um contador que opera na borda de descida de uma rotina de interrupção (ISR) de um dos pinos analógicos do circuito que é conectado ao tubo fotomultiplicador (PMT). A cada ciclo de contagem, este é enviado serialmente pelo cabo USB ao computador, onde através do monitor serial do próprio IDE, pode-se observar a contagem.

No ambiente Processing, o código java utilizado se comunica com o Arduíno e recebe os valores de contagem serialmente. É neste software que foi criado a interface gráfica com botões no qual o usuário pode definir o número de loops e o intervalo de tempo de cada loop em milissegundos, além de um gráfico em tempo real para facilitar a visualização dos dados adquiridos e acompanhar $o$ andamento do experimento.

Os dados também são salvos em um formato .txt ou .csv, a critério do usuário, de modo que este pode criar uma biblioteca de dados, assim como fazer um melhor tratamento deste em outro software de sua escolha.

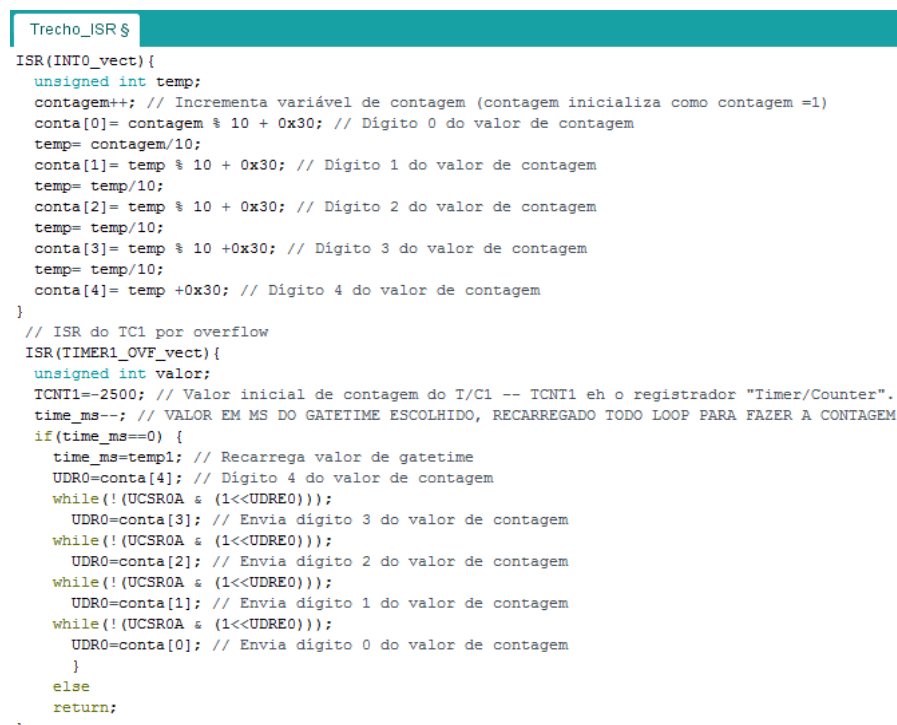

Figura 1. Rotina de interrupção do código C.

\section{Conclusões}

Os códigos, por serem criados em linguagens de fácil acesso, podem também ser alterados para cumprirem com quaisquer novas necessidades que o usuário queira, sendo assim compatíveis para uso em novos experimentos e pesquisas no campo de biofotonica.

\section{Agradecimentos}

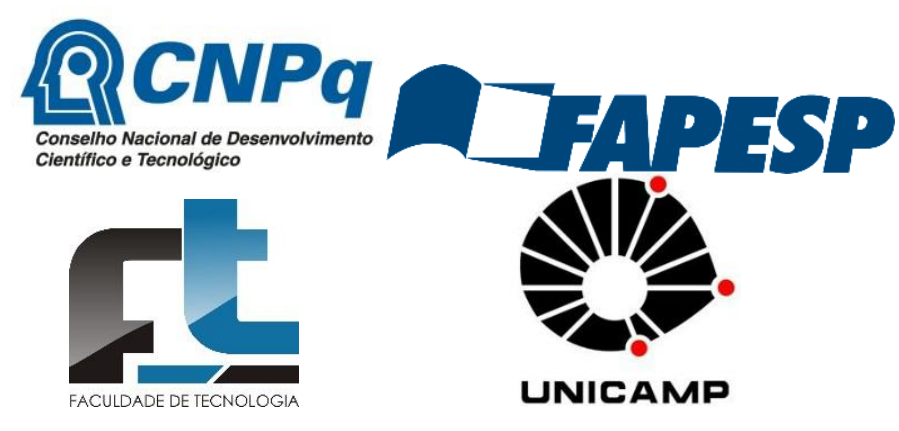

1 BERTOGNA, Eduardo G. Projeto, construção e aplicações de câmara escura portátil para medidas de Bioluminescência ultra-fraca. Tese de Doutorado. Campinas-SP 2013. 